Sosyo

Ekonomi

January-June

2014-1

\title{
Finansal Kalkınma ve Gelir Eşitsizliği: Türkiye Örneği, 1980-2012
}

\author{
Zafer KANBEROĞLU
}

Mehmet Akif ARVAS

zkanberoglu@yyu.edu.tr

aarvas@yyu.edu.tr

\section{Financial Development and Income Inequality: The Turkish Case, 1980-2012}

\begin{abstract}
This study investigates the impact of financial development on income inequality for the Turkish case, over the period 1980 through 2012. For this purpose, an ARDL (Autoregressive Distributed Lag) model is employed. According to the findings, while GDP per capita, inflation rate and private sector credits have reducing effects on income inequality; trade variable increases inequality at a low level. For the Turkish case, as for the effect of financial development on income inequality, it is found that a $1 \%$ increase in private sector credits, on average, leads to a $0.041 \%$ decrease in income inequality for the period under consideration. Therefore it is concluded that private sector credits make a positive contribution to the equity of income distribution in Turkey.
\end{abstract}

Keywords

: Financial Development, Income Inequality, Turkey.

JEL Classification Codes : $\quad$ C32, D31, O16.

\section{Özet}

$\mathrm{Bu}$ çalışma finansal kalkınmanın gelir eşitsizliği üzerinde etkisini Türkiye örneğinde 1980-2012 dönemi için incelemektedir. Söz konusu ilişkiyi test etmek için ARDL yöntemi kullanılmıştır. Çalışmanın ekonometrik bulgularına göre kişi başına gelir, enflasyon ve özel sektör kredileri gelir eşitsizliğini azaltıcı etkilere sahipken, ticaret değişkeninin gelir eşitsizliğini, çok düşük bir seviyede dahi olsa, artırdığ 1 görülmektedir. Bu çalışmanın da esas motivasyon kaynağını oluşturan, finansal gelişmenin gelir eşitsizliği üzerine olan etkisine bakıldığı zaman, Türkiye açısından incelenen dönemde ortalama olarak özel kredi hacminde meydana gelen \%1'lik bir artışın gelir eşitsizliğini yine ortalama olarak \%0.041 oranında azaltarak, gelir dağılımında eşitliğin sağlanması noktasında bir katkı yaptığı sonucu çıkarılabilir. 
Zafer KANBEROĞLU \& Mehmet Akif ARVAS 


\section{Giriş}

Kalkınma ve gelir dağılımı arasındaki ilişki ikinci dünya savaşından bu yana ekonomistlerin ilgilendiği önemli konulardan biri olmuştur. Bu konuda referans kabul edilen Kuznets (1955)'in çalışması önemli bir kilometre taşıdır. Kuznets, ekonomik gelişmenin ilk safhalarında gelir dağılımında bozulma, ilerleyen safhalarda ise gelir dağılımında bir iyileşmeyi yaşanacağı ifade eden Ters- U hipotezini ortaya atmıştır.

Ekonomi yönetimlerinin önemli görevlerinden biri gelir dağılımı konusunda yaşanacak uçurumların ortadan kaldırılmasına çalışmaktır. Zira gelir dağılımında yaşanacak adaletsizlik, sosyo-ekonomik pek çok problemin devamına ya da ortaya çıkmasına neden olabilecektir. Gelir dağılımında yaşanan problemler dönemden döneme, toplumdan topluma değişmekle birlikte Beck, Demirgüç ve Levine (2007), Claessens ve Perotti (2007) gibi pek çok iktisatçıya göre finansal kalkınma doğrudan gelir dağılımını etkilemektedir.

Finansal liberalleşmenin yaşandığı süreçte ise kalkınmanın önemli bir unsuru finans olarak kabul edilmiştir. Bu bağlamda finansal kalkınma ve gelir dağılımı özellikle kalkınma iktişatçıları açısından irdelenmesi gereken bir başlık olmuştur. Bu ilişkinin araştırıldığ çalışmalar özellikle 1990'lı yıllardan sonra yoğunluk kazanmıştır. Bu dönemde Greenwood ve Jovanovic (1990), Galor ve Zeira (1993) ve Banerje ve Newman (1993) finansal kalkınma ve gelir eşitsizliği arasındaki teorik bağın kurulmasında doğrusal olmayan (non-linear) ve doğrusal (linear) olarak ifade edilen iki hipotezi ortaya atmışlardır.

$\mathrm{Bu}$ çalışmada finansal kalkınma ve gelir dağılımı arasındaki ilişki Türkiye örneğinde incelenmeye çalışılacaktır. Çalışmanın ikinci kısmında konu ile ilgili teorik çerçeve sunulmuştur. Üçüncü kısımda literatür taraması yer almaktadır. Dördüncü kısımda veri seti ve ekonometrik yöntem tanıtılmaktadır. Beşinci kısımda analiz bulguları, son kısımda ise sonuç ve değerlendirmeler yer almaktadır.

\section{Teorik Çerçeve}

Finansal kalkınma ve gelir eşitsizliği arasındaki teorik çerçeveyi Kuznets (1955)'den esinlenerek oluşturulan iki hipotez oluşturmaktadır. Bunlardan ilki Greenwood ve Jovanovic (1990) tarafından geliştirilen ve doğrusal olmayan Ters - U Eğrisi (non-linear inverted U-shaped) olarak ifade edilen hipotez, ikinci hipotez ise Galor ve Zeira (1993) tarafından geliştirilen doğrusal hipotez'dir.

Finansal kalkınma ve gelir eşitsizliği arasındaki ilişkiyi açıklamada kullanılan ilk hipotez Green ve Jovanovic (1990) tarafından ortaya atılmıştır. Ters U eğrisi teorisi 
veya doğrusal olmayan hipotez olarak ta bilinen hipotez, Kuznets (1955)'den esinlenerek gelir eşitsizliği ve finansal kalkınma etkileşimini ortaya koymaktadır. Green ve Jovanovic (1990), ekonomik faktörün iki yatırım seçeneğinden birini takip edeceğini varsaymakta; bu seçeneklerden birinin güvenli fakat düşük getiriye sahip olduğunu, diğerinin daha riskli fakat yüksek getiriye sahip olduğunu kabul etmektedir. Bu süreçte aracı hizmetler ortaya çıkar ve aracılık projelerine katılmak isteyen bireyler için farklı yatırım portföyü rolü oynar. Finansal sistemin yeterince gelişmemiş olduğu dönemde, ekonomide kaynak etkinliği ve büyümenin istenen düzeyde olduğundan bahsedilemez. Finansal sistemin gelişmesi ile birlikte kaynakların etkinliğinin artığı görülür. Bununla birlikte, bu süreçte bireyler belli bir refah seviyesi eşiğine ve servete sahip olanlar daha fazla kazançlı çıkarlar. Fakir bireyin söz konusu eşiğe ulaşmak için belli bir zamana ihtiyacı vardır. Böylece zengin-fakir arasındaki gelir farklılığı finansal yapının genişlemesi ve hızlı ekonomik büyüme ile artar. Ekonominin olgunlaşma safhasında, pek çok insan finansal hizmetlere erişebilir. $\mathrm{Bu}$ dönemde ekonomi istikrarlı ve durağan (kararlı) duruma ulaşır ve bu noktadan itibaren gelir eşitsizliği azalmaya başlar.

Nihai olarak Greenwood ve Jovanovic (1990) finans ve eşitsizlik arasındaki ilişkiye dinamik bir çözüm sunmaktadır. Onlara göre finansal aracıların daha az gelişmiş olduğu gelişmenin ilk dönemlerinde, ekonomi yavaş gelişir; ileri gelişme safhasında daha hızlı ekonomik gelişme ve daha derin finansal gelişme ile birlikte gelir eşitsizliği artar. Zamanla, yoğun finansal yapı finansal aracılık sektörüne erişim kazanan daha fazla ekonomik karar birimi ile tamamen gelişir, gelir eşitsizliği azalır ve nihai olarak durağan hale gelir.

Finansal kalkınma ve gelir eşitsizliği arasındaki ilişkiyi açıklamada kullanılan ilk hipotez Galor ve Zeira (1993) tarafından ortaya atılmıştır. Beşeri sermaye yatırımlarının önemine yoğunlaşan ve doğrusal hipotez olarak bilinen bu hipoteze göre bir ekonomide tek bir malı üreten iki sektör olduğunu varsayılmaktadır; vasıf yoğun ve vasıf yoğun olmayan. Bireyler ilki mirasla olan, iki dönem yaşar. Her birey iki mesleki seçeneğe sahiptir: tüm yaşamı vasıflı olmayan bir iş (vasıf yoğun olmayan sektör) veya birinci dönemde beşeri sermayeye yatırım, ikinci dönemde vasıflı olarak çalışmak. Bu hipotez, ekonominin başlangıç noktasında bireylerin miras kalan miktar dışında eşdeğer güce sahip olduğunu kabul etmektedir. İlk dönemde beşeri sermayeye yatırım, ikinci dönemde daha fazla miras bırakma eğilimi görülmektedir. Başlangıçta serveti düşük olanlar, beşeri sermayeye yatırım yapmak isterse borçlanmak zorunda kalırlar. Buna rağmen beşeri sermaye yatııımı bölünemezdir ve borç alma, finansal piyasalar gelişmediğinden dolayı maliyetli ve sınırlayıcıdır. Borç alamayan bireyler tüm yaşamları boyunca vasıfsız olarak kalır, daha az kazanır ve daha az miras bırakır. Bu dönüşüm her nesilde devam eder. Böylelikle, başlangıç serveti zengin ve fakir arasındaki aralığı belirler ve gelir eşitsizliği kaçınılmaz olur. Daha sonra, ekonomi büyümeye başlar; finansal piyasaların kademeli gelişimine yol açılır, kredi hizmetleri genişler, daha az maliyet, daha az kısıt, daha kolay erişim sağlanır. Fakir olanlar vasıflı olarak çalışmak, daha fazla kazanmak ve beşeri sermaye yatırımları 
için daha fazla borçlanma şansına sahip olurlar. Sonuç olarak gelir eşitsizliği azalmaya başlar.

Aynı kuramsal çerçeve Banerje ve Newman (1993)'de görülür. Galor ve Zeira (1993)'den farklı olarak Banerje ve Newman (1993)'de bireyler iki yerine üç mesleki seçeneğe sahiptir ve miras unsuru dikkate alınır. Birey, bölünmez yatırım gerekmeyen ve daha az kazanılan, kendi işinde çalışılan veya bölünmez yatırım gereken bir girişimci olarak, yüksek getirisi olan ücretli bir işçi olarak çalışmayı tercih edebilir. Buna rağmen, sermaye piyasası eksikliklerinden dolayı, sadece zenginler veya borç alabilenlerin bölünmez yatırımlara gücü yetebilir. Miras açısından başlangıç refahı başlangıç gelir eşitsizliğini belirleyen anahtar noktadır. İşte bu sebeple, kredi piyasalarının az gelişmiş olduğu bir ülkede (bölünmez yatırımları finanse etmek için fon artışı güç olan ülke) daha yüksek gelir eşitsizliği hâkim olabilir. Sonuç olarak bu hipotezi savunanlar gelir eşitsizliğinin finansal kalkınma ile negatif ilişkili olduğunu ifade etmektedirler.

Lineer hipotezi savunan Galor ve Zeira (1993) ve Banerje ve Newman (1993) sermaye piyasası eksiklikleri ve başlangıç refahın eşitsiz dağıldığı bir ekonomide, bu eşitsizlik ve refahın daha eşit dağıldığı benzer bir ekonomiden daha yavaş büyüme sürdürüleceğini ifade etmektedir. Yine onlara göre, finansal piyasa gelişimi yoksul haneler için daha geniş ve daha kolay kredi erişimini sağlayacak, finansal piyasa gelişimi, gelir eşitsizliğinin azalmasına yardımcı olacaktır.

\section{Literatür Taraması}

Finansal kalkınma ve gelir eşitsizliği arasındaki ilişki politika yapımcıları için önem arz etmektedir. Bu kapsamda iki değişken arasındaki ilişkiyi inceleyen pek çok çalışma bulunmaktadır. Bu çalışmaların bazıları finansal kalkınmanın gelir eşitsizliği üzerinde olumlu etkisini, bazıları ise olumsuz etkisi olduğunu tespit etmiştir.

Finansal kalkınma ile gelir eşitsizliğini inceleyen Law and Tan (2009) Malezya örneğinde konuyu incelemiştir. 1980-2000 dönemini kapsayan çalışmada ARDL yönteminden yararlanılmıştır. Çalışma bulgularına göre çok zayıf da olsa Malezya'da finansal kalkınmanın gelir eşitsizliğini azalttığı tespit edilmiştir. Ayrıca kamunun kalkınma programlarının kurumsal kalite, ekonomik kalkınma ve düşük enflasyon üzerinde yoğunlaşması, gelir eşitsizliği ile mücadelede önemli olduğu ifade edilmiştir.

Shahbaz ve Islam (2011) finansal kalkınma ve gelir eşitsizliği arasındaki ilişkiyi Pakistan örneğinde incelemişlerdir. 1971-2005 arası dönemi kapsayan çalışmada yıllık veriler kullanılmış ve ARDL sınır testi yönteminde faydalanılmıştır. Çalışma bulgularına göre finansal istikrasızlık kötüleşmesine karşın finansal kalkınma gelir eşitsizliğini azaltmaktadır. Ayrıca organizasyonel yapıyı iyileştirmek için yapılan reformların Pakistan'da gelir eşitsizliğini azaltmaya yardımcı olacağı belirtilmektedir. 
Bittencourt (2010) finansal kalkınma ve gelir eşitsizliği arasındaki ilişkiyi Brezilya örneğinde incelemişler. 1985-1994 dönemini kapsayan aylık verilerin kullanıldığı çalışmada Brezilyanın altı temel bölgesinde söz konusu ilişki araştırılmıştır. Çalışmada toplanmış sıradan en küçük kare (POLs- Pooled Ordinary Least Squares) yöntemi kutlanılmış ve söz konusu dönemde gelir eşitsizliğini azaltmada finansal kalkınmanın etkili olduğuna dair güçlü kanıtlar bulunmuştur.

Akbıyık (2012) finansal kalkınma ve gelir eşitsizliği ilişkisini 60 gelişmiş ve gelişmekte olan ülke örneğinde incelemiştir. 2000-2010 dönemini kapsayan çalışmada Arellano-Bond tahmin yöntemi kullanılmıştır. Çalışma bulgularına göre finansal gelişmişlik ile gelir eşitsizliği arasında negatif doğrusal yönlü ilişki tespit edilmiş. Buna göre finansal gelişmişliğin gelir eşitsizliğini azalttığı ifade edilmektedir. Ayrıca gelişmiş ülkeler dışında, Kuznets'in kalkınma gelir eşitsizliği arasındaki ters U şeklindeki ilişkiye dair kanıt bulunmuş ve gelir eşitsizliği üzerinde kalıcı şokların olmadığına yönelik bulgular tespit edilmiştir.

Baligh ve Pirace (2012), finansal kalkınma ve gelir eşitsizliğini İran üzerinde incelemiştir. 1973-2010 dönemini kapsayan çalışmada sınır testi yaklaşımı kullanılmıştır. Çalışma bulgularına göre finansal kalkınma ve gelir eşitsizliği arasında negatif doğrusal ilişki tespit edilmiş. Buna göre finansal gelişmişliğin gelir eşitsizliğini azalttığı ifade edilmektedir. Ayrıca, finansal sektör gelişimi ile gelir eşitsizliği arasında ters $U$ hipotezine dair kanıt bulunamamış ve yine ekonometrik analiz ışı̆̆ında kurumsal kalitenin İran'da gelir dağılımını azaltmada istatistikî olarak anlamlı olduğuna dair sonuçlar elde edilmiştir.

Beck vd. (2007) finans, gelir eşitsizliği ve yoksulluk arasındaki ilişkiyi toplamda 72 ülke örneğinde incelemiştir. 1960-2005 arası dönem iki ayrı döneme (19602005 ve 1980-2005) ayrılarak söz konusu ilişki incelenmiştir. Çalışmada sıradan en küçük kareler regresyon analizi yapılmıştır. Çalışma bulgularına göre finansal sistemin gelir eşitsizliği ve fakirlik üzerinde önemli bir etkiye sahip olduğu tespit edilmiştir. Ayrıca en fakir grubun gelir dağılımı üzerinde finansal kalkınmanın uzun dönemli etkisinin yaklaşık $\% 40$ ve toplam ekonomik büyüme üzerinde finansal kalkınmanın yaklaşık \%60 etkisinin olduğu ifade edilmektedir.

Hoi ve Hoi (2012) finansal kalkınma ve gelir eşitsizliği arasındaki ilişkiyi Vietnam örneğinde incelemiştir. 2002-2008 dönemini kapsayan çalışmada rassal etki, sabit etki ve Hausman spesifikasyon testi kullanılmıştır. Çalışma bulgularına göre finansal kalkınma gelir eşitsizliğini azaltmada pozitif etkiye sahiptir. Ayrıca finansal kalkınmanın eğitim ile etkileşim halinde bulunduğu zaman gelir eşitsizliğini azaltmada daha etkili olduğunu tespit etmiştir. Yine, finansal sektör gelişimi ile gelir eşitsizliği arasında ters $U$ hipotezine dair kanıtlar bulunmadığı belirtilmektedir. 
Jauch ve Watzka (2012) finansal kalkınma ve gelir eşitsizliği arasındaki ilişkiyi 138 gelişmiş ve gelişmekte olan ülke örneğinde incelemiştir. 1960-2008 dönemini kapsayan çalışmada panel analiz yapılmıştır. Çalışma bulgularına göre teorik modellerin öngördüğü finansal kalkınmanın gelir eşitsizliği üzerinde negatif etkiye sahip olduğu öngörüsü reddedilmekte ve finansal kalkınma ilke gelir eşitsizliği arasında pozitif ilişki tespit edilmiştir.

Vivien (2010) finansal kalkınmanın gelir eşitsizliği ve yoksulluk üzerinde etkisini 78 gelişmiş ve gelişmekte olan ülke örneğinde incelemiştir. 1960-2006 dönemini kapsayan çalışmada panel veri regresyon yöntemi kullanılmıştır. Çalışma bulgularına göre gelir eşitsizliği ve yoksulluk sadece kredi piyasaları ile değil aynı zamanda daha fazla gelişmiş borsalar aracılığıyla azaltılmaktadır. Ayrıca etnik farklılık ve toprak dağılımı gelir eşitsizliği ve yoksulluğun her ikisinin belirlenmesinde önemlidir. Diğer bir bulguya göre, kamu harcamalarının yüksek gelirli ülkelerde gelir eşitsizliğinin azalmasına yol açtığı, buna karşın düşük gelirli ülkelerde herhangi bir etkisi olmadığı tespit edilmiştir.

Zhicheng (2006) finansal kalkınma ve gelir eşitsizliği arasındaki ilişkiyi Çin örneğinde incelemiş̧ir. 1991-2000 dönemini kapsayan çalışmada GMM (Generalized Method of Moment) yöntemi kullanılmıştır. Çalışma bulgularına göre finansal kalkınma ve gelir eşitsizliği arasında negatif doğrusal ilişki tespit edilmiş. Buna göre finansal gelişmişliğin gelir eşitsizliğini azalttığı ifade edilmektedir. Özellikle bu etkinin yapılan reformlar sonrası daha anlamlı olduğu tespit edilmiştir.

Zielschot (2013) finansal kalkınma ve gelir eşitsizliği arasındaki ilişkiyi WIDER (World Income Inequality Database) kapsamındaki ülke örneklerinde incelemiştir. 19602005 dönemini kapsayan çalışmada sıradan en küçük kareler regresyon yöntemi kullanılmışır. Çalışma bulgularına göre finansal kalkınmanın net gelir eşitsizliği üzerinde negatif etkiye sahip olduğu, buna karşın safi gelir eşitsizliği üzerinde etkili olmadığını tespit etmiştir. En yoksul grupta yer alan kesimin finansal kalkınmadan faydalandığı, buna karşın en zengin grupta yer alan kesimin gelir payının azaldığı sonucuna ulaşmıştır.

\section{Veri Seti ve Ekonometrik Yöntem}

$\mathrm{Bu}$ çalışmada gelir eşitsizliği üzerinde finansal gelişmenin etkisini analiz etmek için 1980-2012 yıllık değerleri kullanılmıştır. Çalışmada gelir eşitsizliğini temsilen Gini katsayısı ve finansal gelişme göstergesi olarak yurtiçi özel sektör kredilerin GSYH'deki payı kullanılmıştır. Gelir eşitsizliği üzerinde etkisi düşünülen kişi başı GSYH, enflasyon oranı ve GSYH içinde dış ticaret payı bağımsız değişken olarak kullanılmıştır. Değişkenlerin logaritmik değerleri kullanılmıştır. Çalışmada kullanılan veri setine ilişkin bilgi tabloda sunulmaktadır: 
Tablo: 1

Değişkenlerin Tanımı

\begin{tabular}{|l|l|l|}
\hline Değisşen & Tanım & Kaynak \\
\hline lngini & Gini endeks değerleri & Dumlu ve Aydın (2005), TÜíK \\
\hline lngelir & Kişi başı gayri safi yurt içi hasıla (cari fiyat- milyon \$) & Dünya Bankası \\
\hline lnkredi & Yurtiçi özel sektör kredilerin GSYH'deki payı (\%) & Dünya Bankası \\
\hline lnenf & Tüketici fiyatlarıla enflasyon oranları (\%) & Dünya Bankası \\
\hline lntic & İhracatın ithalatı karşıma oranı (\%) & TÜİK \\
\hline
\end{tabular}

Finansal kalkınmanın gelir eşitsizliği üzerindeki etkisinin tahmin edilmesinde Law ve Tan (2009)'un çalışmalarında kullandığı ekonometrik modelden faydalanılmıştır. Modelin çalışmaya uyarlanmış hali şu şekildedir:

$$
\ln \text { gini }_{t}=\varphi+\alpha_{1} \ln \text { gelir }_{t}+\alpha_{2} \ln \text { kredi }_{t}+\alpha_{3} \ln e n f_{t}+\alpha_{4} \ln t i c_{t}+\varepsilon_{t}
$$

Greenwood and Jovanovic (1990) kalkınmanın ilk evrelerinde eşitsizliğin artacağını, kalkınmanın ileriki aşamalarında eşitsizliğin azalacağını öngörmekte ve dolayısıyla Kuznets'in hipotezini desteklemektedir. Galor ve Zeira (1993) ise finansal kalkınma ile gelir eşitsizliği arasında negatif ilişki beklemektedir.

Değişkenler arasındaki ilişkinin gerçeği yansıtması için serilerin durağan olması gerekmektedir. Serilerin durağan olmaması sahte regresyon sorununa yol açabilmektedir. $\mathrm{Bu}$ sorundan kaçınmak ve serilerin durağanlığını sınamak için birim kök testleri uygulanır. Serilerin durağanlığının araştırılmasında en çok kullanılan yöntemlerden genişletilmiş Dickey-Fuller (ADF) ve Philips-Peron (PP) birim kök testleri uygulanmıştır.

Birim kök testi sonuçları 1şı̆̆ında değişkenlerin aynı dereceden durağan olmamaları ve sinırlı sayıda gözlem olmasından dolayı Pesaran vd. (2001) tarafindan geliştirilen sınır testi (bounds test) ile değişkenlerin bütünleşme dereceleri dikkate alınmadan düzey değerler arasında eş bütünleşme ilişkisi tahmin edilir. Değişkenlerin aynı dereceden durağan olmasını gerekli kılan Engle-Granger ve Johansen tarafindan önerilen eş bütünleşme testlerinden farklı olarak sınır testi, değişkenlerin farklı derecen durağan olmaları ve gözlem sayısının az olduğu durumlarda daha güvenilir sonuçlar vermektedir (Narayan ve Narayan, 2004: 58).

Sınır testi, En Küçük Kareler yöntemi (EKK) ile kısıtlanmamış hata düzeltme modelinin (unrestricted error correction model) tahminine dayanmaktadır. (1) nolu denklemin sınır testi ile tahmin edilen modeli şu şekildedir: 


$$
\begin{aligned}
\Delta \text { gini }_{t}= & \alpha_{0}+\sum_{i=1}^{n} \alpha_{1} \Delta \text { gini }_{t-1}+\sum_{i=0}^{n} \alpha_{2} \Delta \text { gelir }_{t-1}+\sum_{i=0}^{n} \alpha_{3} \Delta \text { kredi }_{t-1}+\sum_{i=0}^{n} \alpha_{4} \Delta e n f_{t-1} \\
& +\sum_{i=0}^{n} \alpha_{5} \Delta \text { tic }_{t-1}+\beta_{1} \text { gini }_{t-1}+\beta_{2} \text { gelir }_{t-1}+\beta_{3} \text { kredi }_{t-1}+\beta_{4} \text { enf }_{t-1} \\
& +\beta_{5} \text { tic }_{t-1}+\varepsilon_{t}
\end{aligned}
$$

Yukarıdaki (2) nolu eşitlikte; $\Delta$ (delta) bağımlı ve bağımsız değişkenlerin gecikmelerinin farkını; "n" gecikme uzunluğunu simgelemektedir. Denklem, EKK ile tahmin edilerek modelde uygun gecikme uzunluğu tespit edilmektedir. Eşitlikte yer alan değişkenlere ilişkin gecikme uzunlukları belirlenirken, hata terimlerinde otokorelasyon olmaması için ardışık bağımlılık testleri yapılmalıdır. Burada gecikme uzunluğunu belirlemede Akaike Bilgi Kriteri (AIC-Akaike's Information Criterion) ve ardışık bağımlılı̆̆ test etmek için de Breusch-Godfrey otokorelasyon testi kullanılmıştır. Bu test, modelde bağımlı değişken Gini'nin gecikmeli değerlerinin yer almasından dolayı DurbinWatson (DW) testi yerine kullanılmıştır.

Sınır testi yaklaşımında eş bütünleşme analizi (2) nolu denklemde yer alan katsayıları kullanarak, $\mathrm{H}_{\mathrm{o}}$ hipotezinin test edilmesi yoluyla yapılmaktadır. Dolayısıyla, Wald testi ile hesaplanan $\mathrm{F}$ istatistiklerinin sağlıklı işlemesi için hata terimlerinde oto korelasyon olmamalıdır. (2) nolu eşitlikte bulunan gecikmeli değişkenlerin katsayılarına sıfır kısıtı getirilerek sıfır hipotezi test edilir. $\mathrm{Bu}$ amaçla aşağıdaki hipotezler oluşturulmaktadır:

$$
H_{0}=\beta_{1}=\beta_{2}=\beta_{3}=\beta_{4}=\beta_{5}=0 \text { (Gini ve onun belirleyicileri arasında uzun }
$$
dönemli ilişki yok)

$$
H_{1}=\beta_{1} \neq ; \beta_{2} \neq ; \beta_{3} \neq ; \beta_{4} \neq ; \beta_{5} \neq 0 \text { (Gini ve onun belirleyicileri arasında uzun }
$$
dönemli ilişki var)

Yukarıda $\mathrm{H}_{0}$ değişkenler arasında uzun dönemli ilişki olmadığını, $\mathrm{H}_{1}$ ise değişkenler arasında uzun dönemli ilişki olduğu ifade etmektedir. Hesaplanan F istatistikleri ile bağımlı değişkenin bir gecikmeli seviye değerinin t-istatistiği Pesaran vd. (2001)'da verilen alt ve üst değerler ile karşılaştırılır. Hesaplanan F-istatistiği kritik üst değerden daha büyükse sıfır hipotezi reddedilir, alt değerden küçükse sıfır hipotezi kabul edilir, alt ve üst kritik değer arasında ise eş bütünleşme olup olmadığına dair karar verilemez. 
Eş-bütünleşme ilişkisinin varlığı tespit edildikten sonra, değişkenler arasındaki uzun ve kısa dönem ilişki gecikmesi dağıtılmış otoregresif model (ARDL) yaklaşımıyla incelenmektedir. Dolayısıyla değişkenler arasında uzun dönemli ilişki için oluşturulan ARDL (p, q, r, s) modeli şu şekildedir:

$$
\begin{aligned}
\Delta \text { gini }_{t}= & \alpha_{0}+\sum_{i=1}^{p} \alpha_{1} \Delta g i n i_{t-1}+\sum_{i=0}^{q} \alpha_{2} \Delta \text { gelir }_{t-1}+\sum_{i=0}^{r} \alpha_{3} \Delta \text { kredi }_{t-1}+\sum_{i=0}^{s} \alpha_{4} \Delta e n f_{t-1} \\
& +\sum_{i=0}^{z} \alpha_{5} \Delta t i c_{t-1}+\varepsilon_{t}
\end{aligned}
$$

Modele yer alan $\boldsymbol{p}, \boldsymbol{q}, \boldsymbol{r}, \boldsymbol{s}$ ve $\boldsymbol{z}$ terimleri ilgili değişken için belirlenen gecikme uzunluklarını temsil etmektedir. ARDL modelinde gecikme uzunlukları en küçük AIC alınarak belirlenmiştir.

\section{Ekonometrik Bulgular}

Zaman serileri analizinde değişkenler arasındaki ilişkinin belirlenebilmesi için serilerin durağan olması gerekir. Genişletilmiş Dickey-Fuller (ADF) ve Phillips-Perron (PP) testi kullanılarak uzun dönem statik modeldeki bütün değişkenlerin eşbütünleşme derecesi test edilir. Aşağıdaki tabloda analizde kullanılan değişkenlerin ADF ve PP birim kök test sonuçları gösterilmektedir.

Tablo: 2

\section{ADF ve PP Birim Kök Testi Sonuçları}

\begin{tabular}{|c|c|c|c|c|c|c|c|c|}
\hline \multirow{3}{*}{$\begin{array}{c}\text { SERI } \\
\text { ADI }\end{array}$} & \multicolumn{4}{|c|}{ ADF Testi } & \multicolumn{2}{c|}{ P-P Testi } & \multicolumn{3}{c|}{ ADF Testi } & P-P Testi \\
\cline { 2 - 9 } & $\begin{array}{c}\text { Düzey, } \\
\text { Trendsiz }\end{array}$ & $\begin{array}{c}\text { Düzey } \\
\text { Trendli }\end{array}$ & $\begin{array}{c}\text { Düzey, } \\
\text { Trendsiz }\end{array}$ & $\begin{array}{c}\text { Düzey } \\
\text { Trendli }\end{array}$ & $\begin{array}{c}\text { Düzey, } \\
\text { Trendsiz }\end{array}$ & $\begin{array}{c}\text { Düzey } \\
\text { Trendli }\end{array}$ & $\begin{array}{c}\text { Düzey, } \\
\text { Trendsiz }\end{array}$ & $\begin{array}{c}\text { Düzey } \\
\text { Trendli }\end{array}$ \\
\hline lgini & $-1.203(1)$ & $-2.369(1)$ & $-1.122(1)$ & $-2.369(1)$ & $-6.803(0)^{*}$ & $-4.996(0)^{*}$ & $-6.959(0)^{*}$ & $-7.728(0)^{*}$ \\
\hline lgelir & $-0.047(1)$ & $-3.052(1)$ & $-0.017(1)$ & $-3.052(1)$ & $-5.949(0)^{*}$ & $-5.943(0)^{*}$ & $-5.951(0)^{*}$ & $-5.942(0)^{*}$ \\
\hline lkredi & $0.176(1)$ & $-0.632(1)$ & $0.176(1)$ & $-0.632(1)$ & $-4.579(0)^{*}$ & $-4.861(0)^{*}$ & $-4.580(0)^{*}$ & $-4.865(0)^{*}$ \\
\hline lenf & $-0.962(1)$ & $-1.393(1)$ & $-1.025(1)$ & $-1.467(1)$ & $-5.958(0)^{*}$ & $-6.093(0)^{*}$ & $-5.978(0)^{*}$ & $-6.290(0)^{*}$ \\
\hline ltic & $-1.052(1)$ & $-7.487(0)^{*}$ & $-0.340(1)$ & $-2.367(* *)$ & $-5.377(0)^{*}$ & $-6.098(0)^{*}$ & $-5.858(0)^{*}$ & $-5.895(0)^{*}$ \\
\hline
\end{tabular}

Tablo: 2'ye göre, ADF ve PP birim kök test sonuçlarına göre; gini, gelir, kredi ve enf değişkenleri $\mathrm{I}(1)$ düzeyinde durağan hale gelirken, tic değişkeni $\mathrm{I}(0)$ düzeyinde durağan hale gelmektedirler. 
Birim kök testi sonuçlarına göre modeldeki değişkenler farklı durağanlık seviyelerine sahiptirler. Değişkenlerin farklı durağanlık seviyelerine sahip olması gelir eşitsizliği ve yabancı sermaye yatırımları arasındaki uzun dönem ilişkinin sınır testi yaklaşımı ile test edilmesinin uygun olduğunu göstermektedir. Sınır testi yaklaşımın uygulanmasına karar verildikten sonra kısıtlanmamış hata düzeltme modelinin, En Küçük Kareler (EKK) yöntemi ile elde edilen tahmin sonuçları Tablo: 3'de sunulmuştur.

Tablo: 3

Kısıtsız Hata Düzeltme Modeli Tahmin Sonuçları

(Bağımlı Değişken: lgini， Tahmin Dönemi: 1980-2012)

\begin{tabular}{|c|c|c|c|}
\hline Değişsen adt & Katsayt & t-ist. & 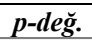 \\
\hline$c$ & 5.3034 & 3.0645 & 0.0120 \\
\hline $\operatorname{lgini}(-1)$ & -1.3784 & -3.0689 & 0.0119 \\
\hline $\operatorname{lgelir}(-1)$ & -0.1082 & -2.9487 & 0.0146 \\
\hline $\operatorname{lenf}(-1)$ & -0.0242 & -2.8517 & 0.0172 \\
\hline lkredit (-1) & 0.0400 & 2.7291 & 0.0212 \\
\hline ltic $(-1)$ & -0.0110 & -0.9068 & 0.3858 \\
\hline dlgini $(-1)$ & 0.5803 & 2.7400 & 0.0208 \\
\hline $\operatorname{dlgini}(-2)$ & 0.4521 & 1.8805 & 0.0894 \\
\hline dlgelir & -0.0836 & -9.9713 & 0.0000 \\
\hline dlgelir $(-1)$ & 0.0290 & 2.5780 & 0.0275 \\
\hline dlgelir $(-2)$ & 0.0202 & 1.1010 & 0.2967 \\
\hline dlenf & -0.0221 & -3.4816 & 0.0059 \\
\hline dlenf $(-1)$ & 0.0084 & 1.6983 & 0.1203 \\
\hline $\operatorname{dlenf}(-2)$ & 0.0114 & 1.3970 & 0.1926 \\
\hline dlkredi & -0.0256 & -4.9722 & 0.0006 \\
\hline dlkredi(-1) & -0.0301 & -1.6529 & 0.1294 \\
\hline dlkredi(-2) & -0.0058 & -0.4751 & 0.6449 \\
\hline dltic & -0.0055 & -0.3309 & 0.7475 \\
\hline $\operatorname{dltic}(-1)$ & 0.0091 & 1.0065 & 0.3379 \\
\hline dltic (-2) & -0.0160 & -1.4878 & 0.1676 \\
\hline \multicolumn{4}{|c|}{ F-stat: $7.6992(0.0010)$} \\
\hline \multirow{2}{*}{\multicolumn{4}{|c|}{ Adj. $R^{2}: 0.8144 \quad D W: 2.2474$}} \\
\hline$A R(2)=0.8535(0.4613$ & $9(0.3464)$ & & \\
\hline \multicolumn{4}{|c|}{$J . B=1.0695(0.5858)$ RESET $=0.0515(0.9501)$} \\
\hline
\end{tabular}

Not: AR(i), Breusch-Godfrey otokorelasyon LM testini; JB ve RESET testleri, sirasıla, normallik testi ve model kurma hatası testini ifade etmektedir. Modelin tanısal test sonuçları tahminin başarılı olduğunu göstermektedir. 
Kısıtsız hata düzeltme modeli tahmin edilirken optimal gecikme uzunluğu, literatürde en sık referans alınan, Akaike bilgi ölçütü (Akaike information criterion-AIC) yardımıyla belirlenmiştir ${ }^{1}$. Testlerin sağlıklı sonuçlar verebilmesi için optimum gecikme uzunluğundaki modelin hata terimleri arasında ardışık bağımlılığın olmaması gerekir. AIC'nin en küçük olduğu gecikme uzunluğunda ardışık bağımlılık sorunu çıktığında bir büyük AIC değerinin olduğu gecikme uzunluğu, optimum gecikme uzunluğu olarak alınır. Maksimum gecikme uzunluğunun sekiz alındığı çalışmada, sınır testi için ardışık bağımlılı̆̆n olmadığı optimum gecikme uzunluğu iki olarak tespit edilmiştir.

Modelin tutarlılı̆̆ (robustness) çeşitli tanısal testler ile sınanmıştır. $\mathrm{Bu}$ testlerden, Breusch-Godfrey oto korelasyon LM testi, Jarque-Bera normallik testi ve Ramsey RESET spesifikasyon testine başvurulmuştur. Test sonuçları modelin arzu edilen ekonometrik özelliklere sahip olduğunu, yani kalıntıların ardışık bağımlı olmadıklarını, normal dağılıma sahip olduklarını ve modelin doğru bir fonksiyonel formda kurulduğunu ifade etmektedir.

Gecikme uzunluğunun belirlenmesinden sonra, değişkenler arasında eşbütünleşme ilişkisinin test edilmesi sürecine geçilmiştir. Sınır testi yaklaşımda değişkenler arasında eş-bütünleşme ilişkisi sıfır $\left(H_{0}=\beta_{1}=\beta_{2}=\beta_{3}=\beta_{4}=\beta_{5}=0\right)$ hipotezinin test edilmesi yoluyla yapılmaktadır. Sıfır hipotezinin kabulü veya reddi $F$ testi ile belirlenmektedir. Hesaplanan F istatistik değeri Pesaran vd. (2001)'deki tablo alt ve üst kritik değerleri ile karşılaştırılır. Birinci durumda, eğer hesaplanan $F$ istatistik değeri alt kritik değerden küçükse seriler arasında eş-bütünleşme ilişkisinin olmadığına karar verilir. İkinci durumda, eğer hesaplanan F istatistik değeri alt ve üst kritik değer arasında kalıyorsa kesin bir yorum yapılamamakta, yani kararsız kalınmaktadır. Bu durumda alternatif eşbütünleşme yöntemleri denenmelidir. Son olarak, eğer hesaplanan F istatistik değeri tablo üst kritik değerini aşıyorsa seriler arasında eş-bütünleşme ilişkisi olduğu kararına varılmaktadır. Buna göre, $\mathrm{H}_{0}$ hipotezini sınamak için, Tablo: 4'te hesaplanan $\mathrm{F}$ istatistik değeri Pesaran vd. (2001)'den alınan kritik değerlerle karşılaştırılmıştır. Bu kritik değerler dört bağımsız değişken ve $\% 10$ anlamlılık düzeyi için verilmiştir.

1 Optimal gecikme uzunluğunun tespitinde referans alınan diğer bir yöntem ise Hendry ve Ericson (1991) tarafindan önerilen yöntemdir. Bu yönteme göre, mutlak değer içerisinde t istatistik değeri birden kü̧̧ük olan serilerin birinci farklarının modelden çıkarılması suretiyle optimal gecikme uzunluğunun tespit edilebileceğini önermektedirler. Detayl bilgi için bknz. Hendry ve Ericson (1991). Modeling the demand for narrow money in the United Kingdom and the United States. European Economic Review, 35, 833-886. 
Tablo: 4

Sınır Testi Sonuçları (Wald Test)

\begin{tabular}{|c|c|c|c|}
\hline \multicolumn{4}{|c|}{$\% 10$ Anlamlılık Seviyesine Ait Kritik Değerler } \\
\hline $\mathrm{k}^{*}$ & F-İstatistiği & Alt Sinır I(0) & Üst Sınır I(1) \\
\hline \hline 4 & $\mathbf{9 . 9 5}$ & $\mathbf{2 . 4 5}$ & $\mathbf{3 . 5 2}$ \\
\hline
\end{tabular}

*k bă̆ımsız değişken sayısını ifade etmektedir. Kritik sınır değerleri için bkz. Pesaran vd., 2001:300, Table C1, Case III.

Tablo: 4'e göre hesaplanan $\mathrm{F}$ istatistik değeri 9.95, kritik üst sınır tablo değeri olan 3.52 'den büyük olduğu için, gelir eşitsizliği, kişi başına gelir, finansal gelişme, enflasyon ve uluslararası ticaret arasında uzun dönemli bir durağan durum ilişkisinin var olduğu sonucuna ulaşılmaktadır. Tanısal testlere ilaveten, tahmin edilen parametrelerin istikrarlığını tespit edebilmek için CUSUM testi kullanılmıştır.

Şekil: 1

CUSUM Testi Grafiği

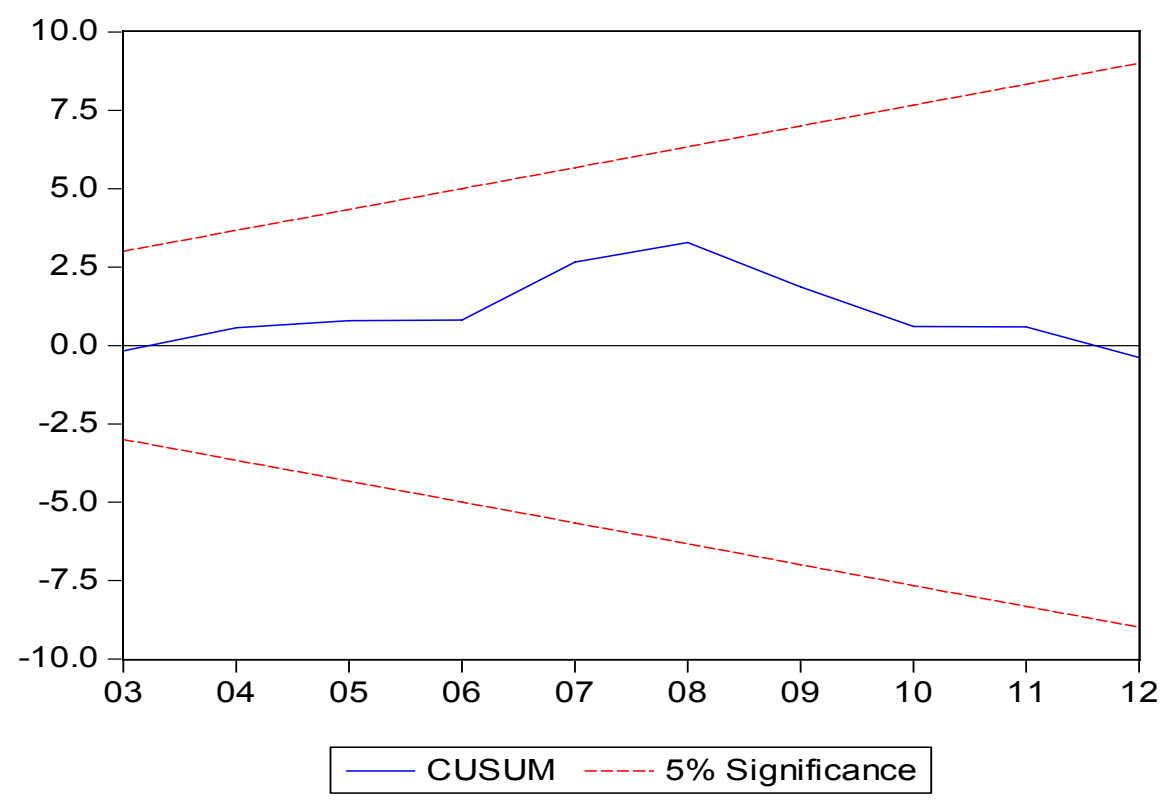

Şekil: 1'e göre CUSUM test istatistiği \%5 kritik bölge içerisinde yer aldığı için, tüm parametrelerin zaman içerisinde istikrarlı oldukları sonucuna ulaşılmaktadır. 
Çalışmada kullanılan değiş̧kenler arasındaki uzun dönem ilişkinin incelenmesi için 3 nolu ARDL modelindeki gecikme uzunlukları AIC yardımıyla belirlenmiştir. Maksimum gecikme uzunluğunun 8 olarak alındığı bu analiz sonucunda, ARDL $(1,1,1,3,1)$ modelinin tahmin edilmesine karar verilmiştir. ARDL $(1,1,1,3,1)$ modelinin sonuçlarına dayanılarak hesaplanan uzun dönem katsayıları Tablo: 5'te sunulmuştur. Uzun dönem ilişkinin tespitinde kullanılan 3 nolu model, tam logaritmik bir model olduğu için elde edilen katsayılar doğrudan uzun dönem esneklikleri verecektir.

Tablo: 5

Uzun Dönem ARDL (1,1,1,3,1) Modeli Tahmin Sonuçları

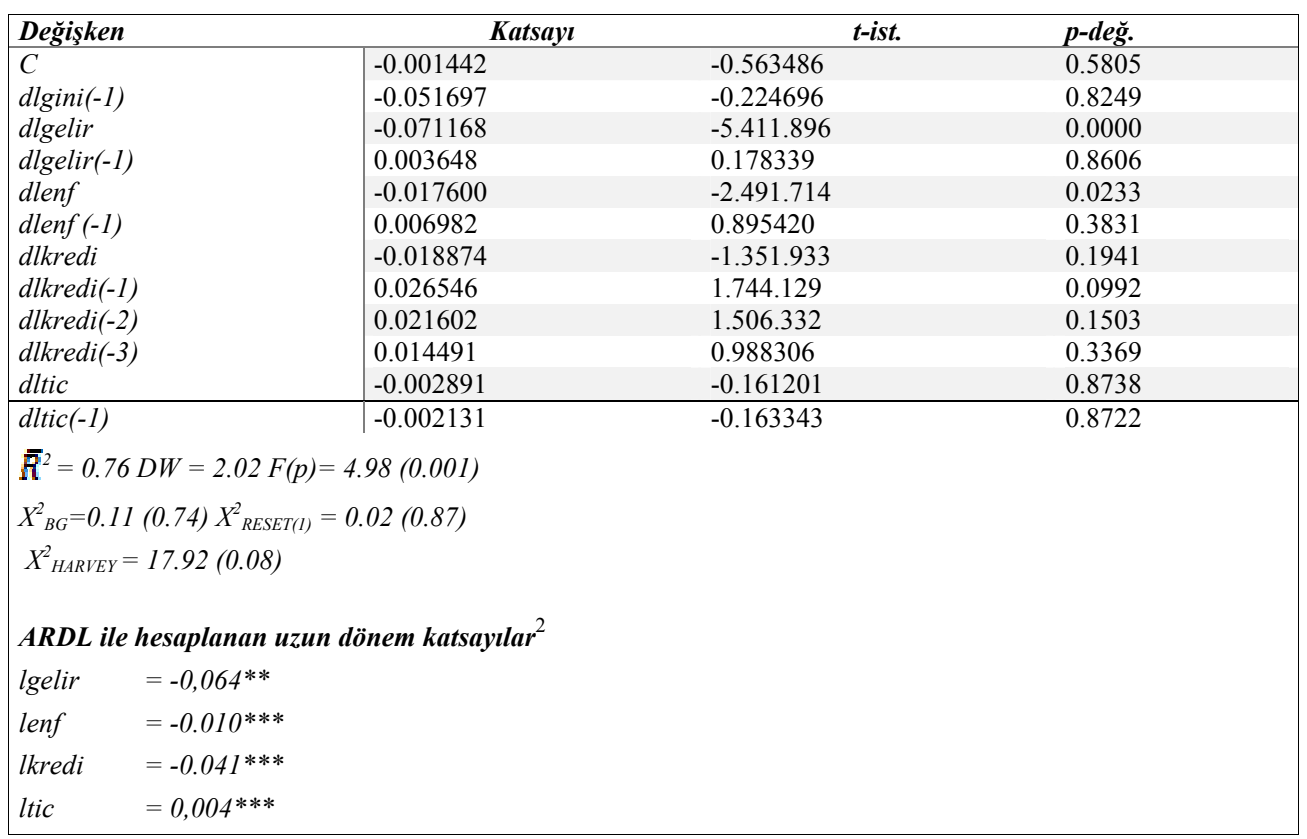

Not: Burada, X2BG Breusch-Godfrey ardışık bă̆ımlılık testi, X2HARVEY Harvey değişen varyans ve X2RESET regresyonda model kurma hatası testini ifade etmektedir. Parantez içerisindeki değerler p-olasılık değerlerini göstermektedir. Modelin tanısal test sonuçları tahminin başarılı olduğunu göstermektedir. Uzun dönem katsayılarına ait olasılık değerleri Bewley yöntemine göre hesaplanmıştır. **/*** sırasıyla \%5 ve \%1 önem düzeyinde anlamlılı̆̆ ifade etmektedir.

Tablo: 5'te, ARDL ile hesaplanan uzun dönem katsayılarının tamamı istatistiki olarak anlamlı bulunmuştur. Bu sonuçlara göre kişi başına gelir, enflasyon ve özel sektör

2 Uzun dönem katsayılarını hesaplama yöntemi için bknz. Johnston, J. ve Dinardo, J. (1997). Econometric Methods, Fourth Edition, McGraw-Hill Companies, United States, 245-247; Greene, W. (2002). Econometric Analysis (5th ed.), Prentice Hall, New Jersey, 562-564. 
kredileri gelir eşitsizliğini azaltıcı etkilere sahipken, ticaret değişkeninin gelir eşitsizliğini, çok düşük bir seviyede dahi olsa, artırdığı görülmektedir. Bu çalışmanın da esas motivasyon kaynağını oluşturan, finansal gelişmenin gelir eşitsizliği üzerine olan etkisine bakıldığı zaman, Türkiye açısından incelenen dönemde ortalama olarak özel kredi hacminde meydana gelen \%1'lik bir artışın gelir eşitsizliğini yine ortalama olarak \%0.041 oranında azaltarak, gelir dağılımında eşitliğin sağlanması noktasında bir katkı yaptığı sonucu çıkarılabilir.

\section{Sonuç}

$\mathrm{Bu}$ çalışma finansal kalkınmanın gelir eşitsizliği üzerinde etkisini Türkiye örneğinde 1980-2012 dönemi için incelemektedir. Bu dönem Türkiye'de finansal serbestleşme yönünde adımlar atılması ve söz konusu adımların ekonomik kalkınmaya etkisinin belirlenmesi adına da önemli bir dönemdir.

Ekonomi yönetimlerinin günümüzdeki temel amaçlarından biri gelir dağılımında adaletin sağlanması olmaktadır. $\mathrm{Bu}$ kapsamda finansal kalkınmanın sağlanması önem arz etmektedir. Finansal kalkınma ve gelir dağılımı ilişkisi 1990'lı yıllarda teorik, 2000'li yıllardan sonra ampirik olarak yoğun bir şekilde incelenmiştir. 1990'l1 yıllarda Türkiye'nin ekonomik verileri de bu anlamda önemlidir. 1994 yılında gelir dağılımı etkileyen enflasyon oranı \%106, kişi başı GSYH 2268 \$, finansal kalkınma göstergesi kabul edilen yurt içi özel kredilerin GSYH'daki payı \%16 iken 2012 yılında enflasyon oranı\%9, kişi başı GSYH 10666 \$, finansal kalkınma göstergesi yurt içi özel kredilerin GSYH'daki payı \%54'e yükselmiştir. Aynı şekilde 1994 yılında gini endeksi 42.858 iken, 2012 yılında 40.200'e endeks değeri düşerek gelir dağılımında eşitsizliğin azaldığını görülmektedir.

Çalışmanın ekonometrik bulgularına göre kişi başına gelir, enflasyon ve özel sektör kredileri gelir eşitsizliğini azaltıcı etkilere sahipken, ticaret değişkeninin gelir eşitsizliğini, çok düşük bir seviyede dahi olsa, artırdığı görülmektedir. Bu çalışmanın da esas motivasyon kaynağını oluşturan, finansal gelişmenin gelir eşitsizliği üzerine olan etkisine bakıldığı zaman, Türkiye açısından incelenen dönemde ortalama olarak özel kredi hacminde meydana gelen \%1'lik bir artışın gelir eşitsizliğini yine ortalama olarak \% 0.041 oranında azaltarak, gelir dağılımında eşitliğin sağlanması noktasında bir katkı yaptığı sonucu çıkarılabilir. Bu bağlamda ekonometrik bulgular, finansal kalkınma ve gelir eşitsizliği arasında negatif ilişki hipotezini desteklemektedir.

Ekonometrik sonuçlar Türkiye özelinde finansal kalkınmanın, ekonomik kalkınmanın önemli bir unsuru olduğunu göstermektedir. Etkin bir finansal sisteme sahip ülkede, gelir dağılımında yaşanan eşitsizliklerin azalacağı ve ülke vatandaşları refah seviyesinde artışların yaşanacağını mümkün görünmektedir. Bu konuda başvurulan teorik 
yaklaşımlarda nihai olarak, finansal kalkınmanın gelir eşitsizliğini azaltacağını ifade ederler. $\mathrm{Bu}$ çalışma temel alınarak yapılacak bundan sonraki çalışmalar için finansal sektörün etkinliğini artıracak kurumsal kalite, finansal büyüklük gibi değişkenlere ait optimal veri seti oluşumuyla bu ilişkinin daha sağlıklı tespitinin yapılacağ düşünülmektedir.

\section{Kaynakça}

Akbiylk, C. (2012), "Cross-Country Evidence On Financial Development-Income Inequality Link", Yayınlanmamıs Yüksek Lisans Tezi, ODTÜ.

Baligh, N. \& K. Pirace (2012), "Financial Development and Income Inequality Relationship in Iran", Middle-East Journal of Scientific Research, 12 (7), 906-914.

Banerjee, A.V. \& A.F. Newman (1993), "Occupational Choice and The Process of Development", The Journal of Political Economy, 101 (2), 274-298.

Beck, T. \& A. Demirgüç Kunt \& R. Levine (2007), “Finance, Inequality And The Poor”, J. Econ Growth, 12, 27-49.

Bittencourt, M. (2010), "Financial Development and Inequality: Brazil 1985-1994", Econ Change Restruct, 43, 113-130.

Claessens, S. \& E. Perotti (2007), "Finance and Inequality: Channels and Evidence", Journal of Comparative Economics, 35, 748-773.

Dumlu, U. \& Ö. Aydın (2008), “Ekonometrik Modellerle Türkiye İçin 2006 Yılı Gini Katsayısı Tahmini", Ege Akademik Bakıs, 8 (1), 373-393.

Greene, W. (2002), Econometric Analysis (5th Ed.), Prentice Hall, New Jersey, 562-564.

Greenwood, J. \& B. Jovanovic (1990), "Financial Development, Growth and The Distribution of Income", The Journal of Political Economy, 98 (5), 1076-1107.

Galor, O. \& J. Zeira (1993), "Income Distribution And Macroeconomics”, The Review of Economic Studies, 60(1), 35-52.

Hendry, D. \& N. Ericson (1991), "Modeling The Demand For Narrow Money in The United Kingdom and The United States", European Economic Review, 35, 833-886.

Hoi, C.M. \& L.Q. Hoi (2012), "Financial Development and Income Inequality In Vietnam: An Emprical Analysis", Journal of Economic Development, 14 (2), 5-25.

Jauch, S. \& S. Watzka (2012), "Financial Development and Income Inequality: A Panel Data Approach", Cesifo Working Papers, No.3687.

Johnston, J. \& J. Dinardo (1997), Econometric Methods, Fourth Edition, Mcgraw-Hill Companies, United States.

Kuznets, S. (1955), "Economic Growth And Income Inequality”, American Economic Review, 45, 128. 
Law, S.H. \& H.B. Tan (2009), “The Role Of Financial Development On Income Inequality in Malaysia”, Journal of Economic Development, 34 (2), 153-168.

Narayan, S. \& P.K. Narayan (2004), "Determinants of Demand of Fiji's Export: An Empirical Investigation", The Developing Economics, 42(1), 95-112.

Pesaran, M.H. \& Y. Shin \& R.J. Richard (2001), "Bounds Testing Approaches to the Analysis of Level Relationships”, Journal of Applied Econometrics, 16, 289-326.

Shahbaz, M. \& F. Islam (2011), "Financial Development and Income Inequality in Pakistan: An Application of ARDL Approach", Journal of Economic Development, 36(1), 35-58.

Vivien, K. (2010), “The Effects of Financial Development on Income Inequality and Poverty", Econstor, No.25.

Zhicheng, L. (2006), "Financial Development and Income Inequality in Rural China 1991-2000", Econstor, No.2006/96.

Zielschot, M. (2013), "Financial Development and Income Inequality: Differanting Between Income Definitions", Master Thesis, Tilburg University. 
Zafer KANBEROĞLU \& Mehmet Akif ARVAS

122 